\title{
Analisis pemasaran sapi potong melalui analisis marjin, transmisi harga, struktur pemasaran, perilaku pemasaran dan kinerja pemasaran
}

\author{
Umi Wisapti Ningsih*, Budi Hartono*, Eko Nugroho* \\ * Lecturer of Socio-economic,Faculty of Animal Husbandry,University of \\ Brawijaya,Indonesia.
}

Correspondence author : uningsih56@yahoo.com

\begin{abstract}
Characteristics of respondents the majority (54.38\%) were at a productive age, in the study area had a low educational background were $89.28 \%$ the elementary school. Respondents $(49.12 \%)$ had more than 20 years of farming experience. Ongole Crossbreed (PO) were the most preferred cattle raised by the majority of respondents $(57.89 \%)$. The respondents mostly $(94.74 \%)$ sold their cattle to the local trader or middlemen. Who sold their cattle directly to the animal market opted Pakis as the most preferred location $(40.35 \%)$. The majority of respondents $(68.42 \%)$ agreed that middlemen played a crucial role in determining the selling price. The selling price of cattle in producers level has a low correlation $(\mathrm{r}=0.32)$ with price in the traders level. Also, the price transmission was low (0.00099). The farmers earned monthly on average Rp 113.160 per animal, the local traders Rp 375.000 per animal. This low-income share caused by the fact that farmers should pay production costs as an amount of $\mathrm{Rp}$ 2.329.772 per animal per year or Rp 194.147 per animal per month.
\end{abstract}

Keywords:beefcattle, marketing structure

\section{PENDAHULUAN}

Catatan Dinas Peternakan Propinsi Jawa Timur yang dilansir TEMPO.C0 (2012), Jawa Timur pada tahun 2011, memiliki populasi ternak sapi potong sebanyak 4.727.298 ekor, jumlah tersebut sebesar $31,80 \%$ dari populasi nasional. Setiap tahun kelahiran sapi yang diperoleh sebanyak 966.000 ekor, untuk mencukupi kebutuhan sendiri di wilayah propinsi JawaTimur dilakukan pemotongan 495.000 ekor, sedangkan dijual keluar wilayah sekitar 148.000 ekor per tahun. Penjualan ternak dilakukan ke daerah Jawa Barat dan DKI Jakarta, bahkan untuk pemasaran sapi dari wilayah kawasan Timur yaitu: Bali, NTT, NTB, melewati propinsi JawaTimur terlebih dahulu untuk sampai pada wilayah yang dituju.

Sistem pemasaran ternak khusus nya sapi potong sampai saat ini masih sederhana, jalur yang dilewati dari produsen sampai ke tangan konsumen masih panjang, peran pedagang dan Blantik yang masih besar dalam jual beli ternak akan menyebabkan harga yang diterima peternak menjadi kecil, karena peternak tidak memiliki posisi tawar. Strategi pemasaran perlu dilakukan agar dapat melaksanakan pemasaran yang efisien, karena dengan pemasaran yang efisien dapat memotivasi peternak dalam meningkatkan usaha, sehingga produktivitas dapat ditingkatkan. Tetapi untuk membuat suatu pengembangan pemasaran perlu dikaji 
terlebih dahulu beberapa faktor baik makro maupun mikro yang mempengaruhi sistem pemasaran agar dapat diketahui kondisi jalur pemasaran, transmisi harga, struktur pemasaran (marketing structure), perilaku pemasaran (marketing conduct) dan kinerja pemasaran (marketing performance). Sehingga dapat meningkatkan kinerja pemasaran, yang dapat menguntungkan kedua belah pihak.

Penelitian ini dilakukan di Kecamatan Jabung Kabupaten Malang berdasarkan pertimbangan bahwa Kecamatan Jabung salah satu daerah berpotensi untuk pengembangan sapi potong dengan jumlah ternak 8.359 ekor dengan jumlah peternak 678 orang.

Penelitian ini bertujuan: 1 . Mengidentifikasi karakteristik peternak, 2 . Menganalisis jalur pemasaran dan margin pemasaran, serta analisis transmisiharga 3. Menganalisis marketing structure, marketing Conduct dan marketing performance dari kondisi pasar yang ada.

Hasil identifikasi dan perhitungan analisis pemasaran sapi potong dapat berguna sebagai: 1. Sumbangan pemikiran untuk memperbaiki kinerja lembaga lembaga pemasaran dan sistem pemasaran, sehingga dapat meningkatkan produktivitas usaha ternak sapi potong. 2. Pengembangan pemasaran usaha ternak sapi potong, dengan melibatkan stakeholders, sehingga dapatmenguntungkan kedua belah pihak.

\section{MATERI DAN METODE}

\section{Tempat dan waktu penelitian}

Penelitian akan dilaksanakan di Desa Sukolilo, Kecamatan Jabung Kabupaten Malang, pelaksanaan penelitian dilakukan selama 4 bulan.

\section{Metode penelitian}

Metode yang digunakan dalam penelitian ini adalah metode survey. Data yang diambil meliputi data primer dan data sekunder. Data primer dikumpulkan dari responden dengan menggunakan tekniik wawancara, serta dilakukan observasi. Sedangkan data sekunder diperoleh dari dinas peternakan Kabupaten Malang, dan Desa Sukolilo Kecamatan Jabung Kabupaten Malang.

\section{Teknik pengambilan sampel}

Pengambilan sampel peternak dilakukan secara sengaja, dimana desa Sukolilo terdiri dari 4 dukuh yaitu: Dukuh Bendo, Gandon Barat, Gandon Timur dan Kampung Anyar. Masingmasing dukuh diambil 15 peternak/ pedagang sebagai sampel penelitian.

\section{Analisa data}

Perhitungan margin pemasaranmenurut Sudiyono (2002), sebagai berikut:

$\mathrm{MP}=\mathrm{Pr}-\mathrm{Pf}$, dimana

$\mathrm{MP}=$ Margin pemasaran,

$\operatorname{Pr}=$ Harga di tingkatpengecer

Pf = Harga di tingkatpetani

Untuk mengetahui apakah margin pemasaran merupakan fungsi harga ditingkat konsumen maka dicari denganmatematika regresi sebagai berikut:

$$
\begin{aligned}
& \operatorname{Pr}=\operatorname{Pf}+\mathrm{M} \\
& \mathrm{M}=\mathrm{a}+\mathrm{b} \operatorname{Pr} \\
& \mathrm{b}=\{(\Sigma \mathrm{M} \cdot \Sigma \mathrm{pr}-\Sigma \mathrm{M} \cdot \Sigma \mathrm{Pr}) / \mathrm{N}\} /\left\{\left(\Sigma \mathrm{Pr}^{2}\right)-\right. \\
& \left.(\Sigma \mathrm{Pr})^{2} / \mathrm{N}\right\}
\end{aligned}
$$

\section{HASIL DAN PEMBAHASAN}

\section{Karakteristik responden}

Karakteristik responden yang diamati dalam penelitian ini meliputi umur, pendidikan, lama pengalaman beternak sapi, asal pengetahuan 
beternak sapi, dan tujuan memelihara sapi. Karakteristik responden dapat dilihat pada Tabel 1

Tabel 1. Karakteristik

\begin{tabular}{|c|c|c|c|}
\hline No & Macam & Jumlah & $\%$ \\
\hline \multirow[t]{3}{*}{1.} & Umur (tahun) & & \\
\hline & $20-45$ & 26 & 45,62 \\
\hline & $46-65$ & 31 & 54,38 \\
\hline \multirow[t]{5}{*}{2.} & Pendidikan & & \\
\hline & SD & 50 & 89,28 \\
\hline & SMP & 3 & 5,35 \\
\hline & SMA & 2 & 3,57 \\
\hline & PT & 1 & 1,78 \\
\hline \multirow[t]{4}{*}{3.} & Pengalaman beternak & & \\
\hline & $5-10$ & 15 & 26,31 \\
\hline & $11-2$ & 14 & 24,56 \\
\hline & $>20$ & 28 & 49,12 \\
\hline \multirow[t]{3}{*}{4.} & Asal pengetahuan beternak & & \\
\hline & Turun Temurun & 37 & 64,92 \\
\hline & Pengalaman dari teman/koperasi & 20 & 35,08 \\
\hline \multirow[t]{4}{*}{5.} & Tujuan pemeliharaan & & \\
\hline & Pembibitan & 12 & 21,05 \\
\hline & Penggemukan & 6 & 10,53 \\
\hline & Tabungan/kombinasi & 39 & 68,42 \\
\hline
\end{tabular}

Sumber: Data primer terolah

Hasil penelitian menunjukan bahwa sebagian besar responden $(54,38 \%)$ berusia antara 46-65 tahun dan mayoritas responden $(89,28 \%)$ hanya berpendidikan tamat sekolah dasar. Namun demikian, mayoritas peternak $(49,12 \%)$ memiliki pengalaman dalam hal budidaya sapi selama lebih dari 20 tahun. Pengetahuan tentang budidaya sapi sebagian besar $(64,92 \%)$ diturunkan secara turun-temurun dari orang tuanya. Mayoritas peternak $(68,42 \%)$ yang memelihara sapi bertujuan untuk pembibitan, penggemukan dan tabungan

\section{Keadaan sapi potong}

Keadaan sapipotong yang dimaksud dalam penelitian ini meliputi jenis sapi yang dipelihara, status kepemilikan sapi dan umur sapi saat pembelian (Tabel 2).

Tabel 2. Keadaan sapi potong

\begin{tabular}{llll}
\hline No & Macam & Jumlah & $\%$ \\
\hline
\end{tabular}




\begin{tabular}{|c|c|c|c|}
\hline \multicolumn{4}{|c|}{ 1. Jenis sapi yang dipelihara } \\
\hline & $\mathrm{PO}$ & $33(1-3)$ & 57,89 \\
\hline & Simental & $5(1-2)$ & 8,77 \\
\hline & Limosin & $19(1-4)$ & 33,33 \\
\hline 2. & \multicolumn{3}{|l|}{ Status kepemilikan } \\
\hline & Milik sendiri & 28 & 49,12 \\
\hline & Milik sendiri dan orang lain & 13 & 22,81 \\
\hline & Milik orang lain & 16 & 28,07 \\
\hline 3. & \multicolumn{3}{|l|}{ Umur sapi saat pembelian (bulan) } \\
\hline & 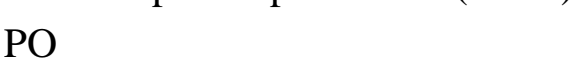 & $2-42$ & \\
\hline & Simental & $8-24$ & \\
\hline & Limosin & $3-30$ & \\
\hline
\end{tabular}

Sumber: Data primer terolah

Jenissapi yang dipelihara responden di wilayah penelitian sebagianbesar $(57,89 \%)$ adalah jenis Peranakan Ongole (PO) dan49,12\% memelihara sapi milik sendiri.

\section{Cara pemasaran dan tujuan pasar}

Peternak $(94,74 \%)$, memasarkan ternak sapi potongnya dengan menjual kepada pedagang/blantik. Terkait dengan biaya pemasaran, transportasi memiliki kontribusi biaya yang berkisar antaraRp 50.000 - Rp 100.000. Selain itu, upah blantik juga memegang porsi yang besar yakni antara $\mathrm{Rp} 25.000$ hingga $\mathrm{Rp}$ 75.000. Hasil penelitian menun- jukanbahwa $(68,42 \%)$ blantik sangat menentukan harga jual sapi. Informasi mengenai harga sapi paling banyak $(68,42 \%)$ diperoleh dari sesama peternak. Hal ini menunjukkan bahwa interaksi antar peternak di daerah penelitian sudah bagus. Hasil perhitungan menemukan bahwa kisaran harga sapi saat pembelian rata-rata sebesar Rp4.900.000 (variasi harga antara Rp2.300.000; - $\mathrm{Rp}$ 15.000.000) dan peternak menjual sapi pada kisaran harga rata-rata Rp8.587.700 (dengan variasi Rp.4.000.000 - Rp 27.000.000;).

Tabel 3. Penentuan harga jual 


\begin{tabular}{clcc}
\hline No & \multicolumn{1}{c}{ Macam } & Jumlah & $\%$ \\
\hline 1. & $\quad$ Penentuan harga jual & 18 & 31,58 \\
& Peternak & 39 & 68,42 \\
& Blantik/pedagang & & \\
2. & $\quad$ Informasi harga sapi & 39 & 68,42 \\
& Peternak & 11 & 19,29 \\
& Blantik/pedagang & 7 & 12,29 \\
& Survey kepasar & & \\
3. $\quad$ Rata - rata harga sapi (Rp) & 4.900 .000 & \\
& Harga sapi saat membeli & 8.587 .700 & \\
& Harga sapi saat menjual &
\end{tabular}

Sumber: Data primer terolah

\section{Kisaranharga sapi}

Perbandingan kisaran harga sapi saat pertama memelihara hingga har- gasapi saat pelaksanaan penelitian disajikan pada Tabel4.

Tabel 4. KisaranhargaSapi

\begin{tabular}{llll}
\hline \multicolumn{1}{c}{ Kisaran umur } & Harga saat pembelian & Kisaran umur & $\begin{array}{c}\text { Harga saat } \\
\text { sekarang }\end{array}$ \\
\hline PO $(2-24)$ & $2.300 .000-8.600 .000$ & PO $(4-42)$ & $\begin{array}{l}4.000 .000- \\
13.000 .000\end{array}$ \\
Simental & $3.000 .000-8.000 .000$ & Simental $(4-22)$ & $\begin{array}{c}5.000 .000- \\
15.000 .000\end{array}$ \\
Limosin $(3-24)$ & $3.500 .000-15.000 .000$ & Limosin $(3-39)$ & $\begin{array}{l}5.000 .000- \\
27.000 .000\end{array}$ \\
\hline
\end{tabular}

Sumber: Data primer terolah

Kisaran harga sapi tertinggi terdapat pada sapi jenis Limosin dimana harga saat pembelian berkisar $\mathrm{Rp}$ 3.500.000 - Rp 15.000.000 untuk sapi Limosin berumur 3-24 bulan. Sedangkan harga sapi limosin berumur 339 bulan saat dilaksanakan penelitian sudah mengalami peningkatan yakni antara Rp 5.000.000 - Rp 27.000.000; Harga sapi P0, umumnya lebih rendah daripada Simental dan Limosin, hal ini karena sapi P0 yang ada di lapang umumnya lebih kecil bentuk badannyadibanding simental dan Limosin.

\section{Jalur pemasaran dan biaya pemeliharaan Sapi Potong}

Beli sapi/ekor

Rp10.100.000;

DOI : 10.21776/ub.jiip.2017.027.0

\section{Jalur pemasaran ternak Sapi Potong}

Umumnya para petani di pedasaan dalam memasarkan ternaknya, tidak pernah datang langsung kepasar, keterlibatan blantik dan pedagang sangat besar. Hal tersebut sudah melembaga karena petani cukup tinggal di rumah saja para pembeli sudah datang. Jauhnya pasar ternak merupakan kendala para petani untuk menjual langsung kepasar ternak. Jalur pemasaran ternak sapi potong yang dilalui oleh pelaku pasar di Desa Sukolilo sepertri terlihat pada gambar 1, sebagai berikut:
PETERNAK SAPI POTONG

54 peternak $(94,74 \%$ 
$3(5,26 \%)$

Dijual/ekor

Rp17.666.600;

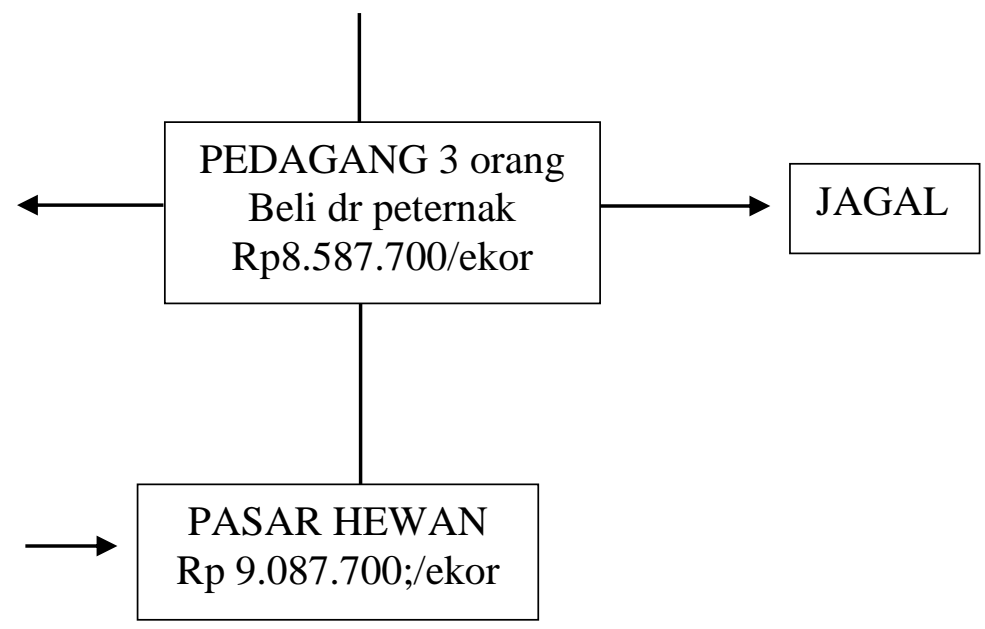

Gambar 1. Jalur pemasaran sapi potong.

Jalur yang dilalui peternak dalam memasarkan sapi potong ada 3 jalur yaitu:

1. Peternak

2. Peternak

3. Peternak

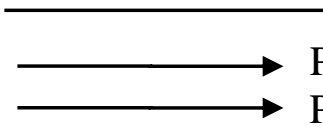

Pasar Hewan

Pedagang $\longrightarrow$ Pasar hewan

Peternak yang menggunakan jalur 1 ada 3 peternak dengan menjual langsung ke pasar hewan. Harga rata-rata ternak saat dibeli adalah $\mathrm{Rp}$ 10.100.000, peternak pada jalur tersebut juga bertindak sebagai pedagang. Jalur ke 2, dilakukan mayoritas peternak, dengan menjual ternaknya melewati pedagang $(94,74 \%)$. Jalur ke 3, terdapat satu pedagang yang meminta bantuan Jagal untuk memotongkan ternaknya dengan keadaan yang sudah siap jual.

\section{Biaya produksi usaha ternak Sapi Potong}

Biaya produksi per ekor per tahun untuk sapi potong sebesar Rp 2.329.772; Biaya tetap yang dimiliki antara lain: cangkul, sabit, sorok, sapu, bangunan kandang dll, sedangkan biaya tidak tetap meliputi pakan, biaya IB, obat- obatan dan tenaga kerja. Biaya tenaga kerja tidak semua peternak menggunakan tenaga luar, hanya 2 peternak yang menggunakan tenaga luar, dengan upah antara Rp 20.000 - Rp 25.000; per hari.

Tabel 5. Rata - rata biaya produksi usaha ternak Sapi Potong per tahun No Macam 


\begin{tabular}{|c|c|c|c|}
\hline \multirow[t]{9}{*}{1.} & Biaya tetap/penyusutan & & \\
\hline & Cangkul & 35.475 & 1,02 \\
\hline & Sabit & 25.000 & 0,72 \\
\hline & Keranjang & 15.769 & 0,45 \\
\hline & Ember & 30.000 & 0,85 \\
\hline & Kandang & 582.072 & 16,66 \\
\hline & Sorok & 25.000 & 0,72 \\
\hline & Sapu & 2.500 & 0,07 \\
\hline & Sub-total & 715.816 & 20,49 \\
\hline \multirow[t]{8}{*}{2.} & Biaya tidak tetap & & \\
\hline & Pakan hijauan & 2.196 .000 & 62,84 \\
\hline & Pakan tambahan & 282.842 & 8,09 \\
\hline & IB & 60.000 & 1,72 \\
\hline & Obat - obatan & 240.000 & 6,86 \\
\hline & Sub-total & 2.778 .842 & 79,51 \\
\hline & Total biaya & 3.494 .658 & \\
\hline & Biaya per ekor/tahun & 2.329 .772 & \\
\hline
\end{tabular}

Sumber: data primer terolah

Keuntungan yang diperoleh peternak selama setahun per ekor : Rp $8.587 .700 ; \quad-\quad(R p \quad 4.900 .000 ;+\quad R p$ 2.329.772;) = Rp 1.357.928; Atau $R p$ 113.160/bulan; melihat hasil keuntungan tersebut relatif kecil, tetapi hasil tersebut sudah membantu ekonomi keluarga sebagai tabungan dan usaha sampingan. Biasanya peternak tidak memperhitungkan biaya yang dikeluarkan, jadi merasa selisih dari harga beli awal dan harga saat dijual sudah merupakan keuntungan yang diperoleh.

\section{Biaya pemasaran}

Biaya pemasaran ditanggung oleh pedagang, pedagang apabila membeli dari peternak dan langsung dijual ke pasar mengambil keuntungan Rp 500.000; per ekor. Kadangkala pedagang juga beternak sendiri dirumah, dengan kurun waktu pemeliharan 8-12 bulan, tetapi apabila harga baik, meski belum batas waktu pemeliharaan ternak tersebut dijual. Terdapat seorang pedagang menjual dalam bentuk sudah dipotong, pelaksanaan pemotongan dilakukan di rumah potong hewan, sebagai gambaran dari penjualan yang dilakukan pedagang dalam bentuk daging,sebagai berikut: misalnya ternak potong dengan berat hidup $500 \mathrm{~kg}$ dengan kisaran harga 1516 juta, maka akan menghasilkan: karkas $240 \mathrm{~kg}$, dengan berat daging lebih kurang $170 \mathrm{~kg}$. Informasi harga dari masing-masing hasil pemotongan sebagai berikut :

a. Harga daging : Rp74.000 Rp.84.000; berat $170 \mathrm{~kg}$

b. Harga kulit : Rp 700.000 dengan berat $35 \mathrm{~kg}$

c. Kepala : Rp 20.000;/ kg berat kepala $8 \mathrm{~kg}$

d. Ekor : Rp 70.000;/kg berat $3 \mathrm{~kg}$

e. Hati : Rp 65.000;/kg berat $5 \mathrm{~kg}$

f. Jeroan : Rp 40.000;/kg berat $15 \mathrm{Kg}$

g. Tulang : Rp $40.000 / \mathrm{kg}$ berat $70 \mathrm{~kg}$ 
Ternak apabila dijual dalam bentuk daging maka peternak/pedagang akan mendapatkan hasil penjualan sebasar Rp 16.595.000;. penjualan tersebut belum termasuk didih yang seringkali dijual oleh para pedagang daging. Ongkos pemotongan ternak apabila hanya memotong saja per ekor Rp 15.000; apabila sudah dalam bentuk terpisah dan siap jual maka per ekor Rp 100.000;. Biaya pemasaran yang dikeluarkan pedagang untuk memasarkan ternak ke pasar hewan per ekor sebagai berikut :

a. Retribusi pasar : Rp 5.000;

b. Transportasi :Rp 50.000;

c. Upah :Rp 50.000; d. Pakan :Rp 20.000;

Total biaya pemasaran per ekor dalam satu kali pemasaran adalah : Rp 125.000;. Apabila dihitung berdasarkan hasil penjualan ternak maka harga ratarata di tingkat pedagang $\mathrm{Rp} 9$. 087.700; dan harga ditingkat peternak Rp 8.587.700; maka margin pemasarannya adalah Rp 500.000; per ekor ternak dewasa. Pedagang setiap ekor, setiap pasaran menerima keuntungan $\mathrm{Rp}$ 375.000; atau Rp 3.000.000 setiap bulan, ada satu pedagang setiap pasaran dapat menjual lebih kurang 10 ekor ternak dengan dua kali pemasaran setiap minggunya. Sehingga setiap pasaran dapat memperoleh keuntungan $\mathrm{Rp}$ 3.750.000; Apabila dibandingkan dengan peternak keuntungan pedagang termasuk sangat besar, peternak per bulan hanya menerima Rp 113.160; seandainya pakan ternak yang berupa hijauan tidak diperhitungkan maka peternak setiap bulan mendapat keuntungan Rp 235.160;/bulan.

\section{Transmisi harga}

Hasil perhitungan korelasi antara harga ditingkat peternak dan pedagang memilki $r=0,32$, sehingga korelasinya lemah, dan integrasi pasarnya tidak efisien.

$$
\begin{aligned}
& P_{f}=b_{o}+b_{1} P_{r}=-442,41+946,138 P_{r} \\
& 1.183 .170 .492 \\
& r=\text {-------------------- }=0,32 \\
& \text { 3.663.906.591 }
\end{aligned}
$$

$\mathrm{ET}=\frac{1}{\mathrm{~b}_{1}} \times \frac{\mathrm{P}_{\mathrm{f}}}{\mathrm{P}_{\mathrm{r}}}$

$\mathrm{ET}=\frac{1}{946,138} \times \frac{8.587 .701}{9.087 .559}$

$\mathrm{ET}=0,001057 \times 0,944995$

$\mathrm{ET}=0,0009988$

Elastisitas transmisi harga atau biasanya disebut transmisi harga adalah suatu angka yang digunakan untuk melihat kaitan antara harga ditingkat produsen akibat perubahan harga di tingkat konsumen. Hasil penelitian menemukan nilai elastisitas transmisi adalah : 0,00099. Hal ini menunjukan bahwa laju perubahan harga ditingkat peternak sangat kecil dibandingkan dengan laju perubahan harga di tingkat pengecer. Pasar tersebut bersaing tidak sempurna dan tidak efisien.

Pendekatan struktur, prilaku dan
penampilan pasar

\section{Struktur pasar}

Struktur pasar adalah bentuk organisasi yang mempengaruhi strategi pasar, berdasarkan penelitian tentang struktur pasar dapat diperoleh hasil bahwa: 1. di Pasar Tumpang, Singosari dan Pakis jumlah pedagang sapi banyak ditemukan. Tetapi penjual ternak dari peternak yang langsung ke pasar jarang terjadi. Sehingga harga ternak di pasar ditentukan oleh para perantara, baik 
blantik, pedagang desa dan pedagang antar kota. 2. Jumlah pembeli (pedagang antar kota) yang ke pasar sedikit, hanya saja para pedagang desa seringkali habis terjual dagangannya. Jumlah penjual dan pembeli akan berpengaruh pada bentuk pasar yang terjadi, apabila penjual banyak dan barangnya homogen maka terjadilah pasar persaingan sempurna. Kalau pembeli hanya sedikit maka terjadi pasar yang oligopsoni. 3. Kemudahan masuk dan keluar pasar, para pedagang baik penjual atau pembeli mudah keluar-masuk ke pasar, konsumen peroranganpun dapat masuk kepasar untuk mencari ternak yang akan dibelinya, tetapi jarang sekali mendapatkan ternak dari produsen/ peternak langsung. Hal tersebut terjadi karena sulitnya transportasi dan jarak pasar yang cukup jauh dari rumah para peternak. 4. Pengetahuan konsumen terhadap harga, konsumen disini adalah para pedagang dan jagal, untuk informasi harga umumnya konsumen lebih faham, karena jaringan antar pedagang ini sangat kuat, sehingga informasi- informasi tentang pemasaran diperoleh sangat cepat.

\section{Perilaku pasar}

Perilaku pasar merupakan proses/gerak yang terjadi di pasar, faktor yang berkaitan dengan perilaku pasar antara lain penentuan kualitas, praktek tidak jujur, persaingan dan kolusi antar pedagang, promosi dan biaya pemasaran. Kualitas ternak yang dijual hanya dilihat secara fisik saja, biasanya dari penampilan gemuk dan kurusnya ternak para pedagang sudah dapat menentukan harga ternak yang dipasarkan. Pengalaman jual beli para pedagang yang sudah bertahun tahun sudah dapat memperkirakan harga dan sehat tidaknya ternak, bahkan salah satu pedagang dapat memperkirakan perbandingan karkas dan daging yang dihasilkan. Sedangkan untuk kualitas organ dalam seperti hati, hanya dapat diketahui kalau ternak telah disembelih. Praktek tidak jujur dalam proses perdagangan ternak antar blantik dan pedagang berdasarkan penelitian ada/dilakukan, dalam hal harga ternak, kadangkala informasi harga tidak diinformasikan sehingga meskipun harga naik, membeli ke peternak dengan harga murah. Persaingan antar blantik dan pedagang ada tetapi tidak sering terjadi untuk mendapatkan ternak, tetapi untuk pembeli ternak dipasar sering antar blantik pasar saling bersekongkol untuk menutupi harga yang sebenarnya. Promosi untuk pemasaran jarang dilakukan oleh pedagang, karena para pedagang adalah pedagang antar kecamatan sehingga tidak perlu melakukan promosi. Ternak yang dibawa ke pasar kebanyakan laku dijual sehingga tidak mengalami kesulitan dalam pemasaran. Untuk memasarkan ternak diperlukan biaya antara lain: biaya transport, biaya pakan saat dipasarkan, upah penjaga ternak, biaya tersebut masih normal/efisien dibandingkan dengan pendapatan yang diperoleh pedagang. Hanya saja kalau ternak tersebut dijual sampai keluar propinsi, biaya transportasi yang besar menjadi beban pedagang

\section{Penampilan pasar}

Penampilan pasar bisa didekati dari: share produsen, ketersediaan produk, peningkatan penjualan dan tehnologi. Rata-rata peternak per bulan menerima pendapatan Rp 113.160; sedangkan pedagang setiap pasaran atau seminggu 2 kali pasaran, mendapat pendapatan Rp 375.000;/ekor. Share peternak sangat kecil dibanding dengan share untuk pedagang, kecilnya share yang diterima peternak disebabkan karena para peternak mengeluarkan 
biaya untuk pemeliharaan per ekor per tahun adalah $\mathrm{Rp} 2.329 .772$; atau Rp 194.147;/bulan/ekor., sedangkan penjualannya tidak langsung ke pedagang antar daerah, tetapi melalui pedagang desa terlebih dahulu. Ketersediaan sapi tidak dapat terintegrasi, hal ini dikarenakan tujuan pemeliharaan yang berbeda antar peternak, mayoritas adalah untuk tabungan, jadi menjualnya kalau peternak memiliki kebutuhan. Adanya larangan impor sapi, berpengaruh pada ketersediaan sapi, sehingga banyak sapi lokal yang dipotong. Untuk peningkatan penjualan, bagi para peternak karena pemeliharaan hanya berkisar 1-3 ekor, kondisi penjualan stagnan, sedangkan untuk pedagang, penjualan naik turun dengan rata-rata kisaran antara 7-10 setiap pasaran. Pemanfaatan tehnologi belum banyak dilakukan, masih sederhana, tehnologi informasi hanya melalui hand phone, sedangkan untuk pemasaran lewat internet belum dilakukan. Demikian halnya penentuan berat ternak tidak dilakukan penimbangan hanya berdasarkan taksiran.

\section{KESIMPULAN}

1. Usia Peternak dan Pedagang termasuk usia produktif, mayoritas peternak berpendidikan SD dengan berpengalaman peternak kurang lebih 20 tahun. Jenis ternak yang dipelihara $57,89 \%$ adalah Peranakan Ongole dengan status kepemilikan milik sendiri ( 49,12\%).

2. Peternak menjual ternaknya kebanyakan ke pedagang/belantik. Harga jual ditentukan oleh pedagang, kisaran harga beli ratarata $\operatorname{Rp} 4.900 .000$ dan harga jual $\mathrm{Rp} \quad 8.587 .700$ dengan usia pemeliharaan kurang lebih 1 tahun. Terdapat satu peternak yang merangkap sebagai pedagang dengan menual ternaknya langsung ke pasar hewan serta melakukan pemotongan ternak dengan dibantu jagal.

3. Biaya produksi yang dikeluarkan per ekor per tahun rata-rata $\mathrm{Rp}$ 2.329.772 dengan keuntungan yang diperoleh $\mathrm{Rp}$ 1.357.928. sedangkan pedangang setiap ekor mengambil keuntungan $\mathrm{Rp} 375.000$ dengan melakukan penjualan $2 \mathrm{x}$ setiap minggu (ternak yang dijual kurang lebih@10 ekor).

4. Hubungan antara perubahan harga di tingkat konsumen dan produsen tidak efisien karena memiliki angka korelasi 0,32 dan elastisitas transmisi 0,00099.

5. Pendekatan struktur pasar kurang efisien, hal ini disebabkan peternak tidak menjual langsung ke pasar. Jumlah pembeli/pedagang lebih sedikit maka terjadi pasar yang oligopsoni. Perilaku pasar dalam menentukan kualitas hanya berdasarkan fisik ternak. Dalam menentukan harga praktek tidak jujur sering terjadi terutama dalam informasi harga terhadap peternak. Share yang diterima produsen sangat kecil yaitu Rp 113.160/ekor

\section{SARAN}

Perlu peran pemerintah dalam membentuk kelembagaan yang berfungsi untuk menjembatani proses jual beli ternak sehingga bisa menguntungkan pihak peternak.

\section{DAFTAR PUSTAKA}

Alma,B.2004.Manajemen Pemasaran dan Pemasaran Jasa.Penerbit ALFABETA. Bandung.

Asri, M. 1991. Marketing. Penerbit dan percetakan

AMP.YKPN.Yogyakarta

Chandra,G.2001. Pemasaran Global. 
Penerbit ANDI Yogyakarta.

Croningen, C.V, Devitt, C.J.B, Wilton, J.W and Cranfield, J.A.L. 2006. Economic evaluations of beef Bulls in an integrated supply chain. Journal of Animal Science. J ANIM SCI 2006, 84: 3219-3227.

Huyen,L.T.T, Herold, P and Zirate,A.V.2010. Farm types for beef production and their economic Success in a mountainous province of northern Vietnam. Journal Agricultural Systems. 103(2010) 137-145

Kotler. $1997 . \quad$ Manajemen Pemasaran.Prehallindo.edisi 9.Jakarta
Mangkunegara, A.B. 2009. Perilaku Konsumen.PT Refika Aditama. Bandung.

Pemerintah Kabupaten Malang. 2013. Selayang Pandang Kabupaten Malang. Website resmi Pemerintah Kabupaten Malang. Diakses pada tanggal 21 Oktober 2013.

http://www.malangkab.go.id/kon ten-85.html

Simamora, Bilson. 2003. Memenangkan Pasar.PT Gramedia Pustaka Utama.Jakarta

Soekartawi.1993. Manajemen Pemasaran Hasil Hasil Pertanian: Teori dan Aplikasinya. Rajawali Press. Jakarta.

Sudiyono, A. 2002. Pemasaran Pertanian. UMM Press. Penerbit Universitas Muhamadiayah Malang. 